\title{
FITOSSOCIOLOGIA DE PLANTAS DANINHAS EM ARROZ IRRIGADO NO SISTEMA DE CULTIVO CLEARFIELD ${ }^{\circledR}$
}

\section{WEED PHYTOSOCIOLOGY SURVEY IN FLOODED RICE CULTIVATED ON CLEARFIELD ${ }^{\circledR}$ SYSTEM}

Anelise Lencina da Silva ${ }^{\mathrm{a}}$, Nereu Augusto Streck ${ }^{\mathrm{b}}$, Roberto Avila Neto ${ }^{\mathrm{a}}$, Cassiano Salin Pigatto ${ }^{\mathrm{a}}$, Mariana Macedo ${ }^{\mathrm{a}}$, Vladison Flogliato Pereira ${ }^{\mathrm{b}}$, André da Rosa Ulguim ${ }^{\text {a }}$

${ }^{a}$ Departamento de Defesa Fitossanitária, Universidade Federal de Santa Maria, Rio Grande do Sul, Brasil. ${ }^{\mathrm{b}}$ Departamento de Fitotecnia, Universidade Federal de Santa Maria, Rio Grande do Sul, Brasil.

*Autor correspondente: andre.ulguim@ufsm.br.

\section{INFORMAÇÕES DO ARTIGO}

\section{Histórico do artigo:}

Recebido: 17 Junho 2020.

Aceito: 05 Outubro 2020.

Publicado: 10 Dezembro 2020.

\section{Palavras-chave/Keywords:}

Cyperus/ Cyperus.

Echinochloa/ Echinochloa.

Mapeamento/ Mapping.

Oryza satival. Oryza sativa.

\section{Financiamento:}

Fundação de Amparo à Pesquisa do Rio Grande do Sul (FAPERGS), pelo apoio financeiro através do Edital $01 / 2017$.

Direito Autoral: Este é um artigo de acesso aberto distribuído sob os termos da Licença Creative Commons, que permite uso, distribuição e reprodução irrestritos em qualquer meio, desde que $\mathrm{o}$ autor e a fonte originais sejam creditados.

\section{Citação deste artigo:}

SILVA, A. L.; STRECK, N. A.; AVILA NETO, R.; PIGATTO, C. S.; MACEDO, M.; PEREIRA, V. F.; ULGUIM, A. R. Fitossociologia de plantas daninhas em arroz irrigado no sistema de cultivo Clearfield ${ }^{\circledR}$. Revista Brasileira de Herbicidas, v. 19, n. 3. 2020.

\begin{abstract}
RESUMO
O manejo de plantas daninhas é essencial para a obtenção de elevadas produtividades de grãos na cultura de arroz irrigado. Neste estudo, teve-se, como objetivos, mapear, quantificar e avaliar a ocorrência de resistência de plantas daninhas em áreas de produção de arroz irrigado com o sistema Clearfield ${ }^{\circledR}$ (CL) no estado do Rio Grande do Sul (RS). Para isso, foi realizado um levantamento fitossociológico por meio de coletas georreferenciadas de solos em 36 propriedades com o cultivo de arroz irrigado, em 16 cidades do RS. As amostras de solo foram acondicionadas em bandejas de polietileno com $792 \mathrm{~cm}^{2}$ de área e dispostas em casa-de-vegetação, a fim de permitir a emergência de plantas daninhas durante o período de outubro de 2018 a junho de 2019. As plantas daninhas presentes foram quantificadas e identificadas em nível de gênero, com auxílio de bibliografia especializada. As variáveis analisadas foram frequência, frequência relatativa, densidade, densidade relativa, abundância, abundância relativa e índice de valor de importância. Foram identificados 38 gêneros, distribuídos em 20 famílias, e as mais representativas foram Poaceae, Cyperaceae e Asteraceae. Os gêneros Cyperus, Echinochloa, Oryza e Lolium apresentaram os maiores índices de valor de importância. Os três primeiros evidenciaram elevada frequência e ampla distribuição nas regiões produtoras de arroz irrigado. As áreas com o cultivo de arroz irrigado, no sistema CL, apresentaram uma alta diversidade e distribuição de plantas daninhas. Plantas daninhas do gênero Cyperus possuem maiores valores de frequência, densidade e abundância relativas, bem como alto índice de valor de importância dentre as que foram observadas.
\end{abstract}


A. L. SILVA

\section{Introdução}

O estado do Rio Grande do Sul (RS) é o maior produtor de arroz no Brasil, responsável por cerca de 77\% da oferta nacional do cereal. Na safra 2018/19, a produção desse grão, no RS, foi correspondente a 7.4 milhões de toneladas, com produtividade média de 7.5 ton ha ${ }^{-1}$ de grãos, cultivados em aproximadamente 1 milhão de hectares no sistema irrigado por inundação (IRGA, 2019). No entanto, no que tange à produtividade, ainda deve-se buscar evoluir, visto que o potencial produtivo da cultura pode atingir 14 ton $\mathrm{ha}^{-1}$ de grãos de arroz (RIBAS et al., 2016).

Dentre os fatores que podem interferir negativamente na produtividade e na qualidade de arroz destacam-se as plantas daninhas. As lavouras de arroz irrigado, no Sul do Brasil, apresentam uma ampla diversidade de espécies de plantas daninhas com elevadas infestações. Dentre as principais plantas daninhas destacam-se o arroz-daninho (Oryza sativa L.), capim-arroz (Echinochloa spp.), junquinho (Cyperus spp.), cuminho [Fimbristylis miliaceae (L.) Vahl. ], papuã [Urochloa plantaginea (Link) R.D. Webster], mihã (Digitaria spp.), aguapé-de-flecha (Sagittaria montevidensis Cham. \& Schlecht), e angiquinho (Aeschynomene spp.) (SOSBAI, 2018). Os prejuízos ocasionados por essas plantas derivam, principalmente, da competição pelos recursos do meio, como o capim-arroz em que uma planta $\mathrm{m}^{-2}$ competindo com diferentes cultivares de arroz foi responsável por perdas de $1,5 \%$ a $55,2 \%$ na produtividade de grãos da cultura (ZHANG et al., 2017). Além disso, a presença de plantas daninhas pode gerar o aumento dos custos de produção e a depreciação do produto final.

A introdução do sistema de cultivo Clearfield ${ }^{\circledR}$ (CL) no ano de 2004 proporcionou o controle seletivo de arrozdaninho em arroz irrigado e de outras espécies daninhas, podendo ser considerado a principal ferramenta para o manejo da planta daninha (MARCHESAN et al., 2011; MENEZES et al., 2009). Todavia, com o uso exclusivo e consecutivo dessa ferramenta houve a seleção de plantas daninhas resistentes (ULGUIM et al., 2019), dificultando o manejo nessas áreas e onerando os custos de produção. Há estimativa de aumento de mais de $200 \%$ do custo de produção mediante a presença de resistência de plantas daninhas em arroz irrigado desde o lançamento da tecnologia CL (MEROTTO et al., 2016). Assim, o aumento dos casos de plantas daninhas resistentes a herbicidas, aliada às mudanças necessárias para o seu manejo, podem representar em alteração na composição florística das áreas de produção.

Um dos métodos mais utilizados para estudar as relações entre a ocorrência das plantas daninhas e o método de manejo utilizado em comunidade infestante é o levantamento fitossociológico (ERASMO; PINHEIRO; COSTA, 2004). Os estudos fitossociológicos podem ser conceituados como a ecologia quantitativa de comunidades vegetais, envolvendo as inter-relações de espécies vegetais no espaço e, de certa forma, no tempo, que tem como objetivo identificar a composição e distribuição de espécies de uma determinada comunidade de plantas (CONCENÇO et al., 2013). Em conjunto com os estudos fitossociológicos, o mapeamento de populações de plantas é outra ferramenta importante para o manejo de plantas daninhas. A distribuição e mapeamento de plantas daninhas nas áreas de cultivo auxiliam na tomada de decisão e método de controle a ser adotado (CHRISTENSEN et al., 2011).

Práticas específicas de manejo podem ser adotadas a partir do conhecimento das espécies predominantes e da ocorrência de resistência a herbicidas nas áreas de cultivo agrícola. Diante do exposto, o objetivo desse trabalho foi mapear, quantificar e avaliar a ocorrência de resistência de plantas daninhas em áreas de produção de arroz irrigado, no sistema Clearfield ${ }^{\circledR}(\mathrm{CL})$, no estado do Rio Grande do Sul (RS).

\section{Material e Métodos}

O estudo foi dividido em duas partes, sendo a primeira relacionada à fitossociologia de plantas daninhas nas áreas de produção e o segundo de avaliação da sobrevivência de plantas após aplicação de herbicida. Para a realização do estudo, amostras de solo foram coletadas em 36 propriedades rurais com o cultivo de arroz irrigado com o sistema CL, situadas em 16 municípios, localizados em cinco das seis macrorregiões orizícolas (IRGA, 2019) do estado do Rio Grande do Sul (Figura 1), na safra agrícola de 2018/19. As coletas de solo foram realizadas antes da semeadura da cultura do arroz irrigado, na camada de 00-10 $\mathrm{cm}$ de profundidade, em área representativa de cada propriedade estudada. Todos os pontos de coleta foram georreferenciados por meio da utilização do Global Positioning System (GPS). Posteriormente, as amostras de solo foram encaminhadas para casa-de-vegetação, localizada na Universidade Federal de Santa Maria (UFSM), para a realização do levantamento fitossociológico.

A partir disso, a fim de promover a emergência das plantas daninhas, as amostras com volumes que variaram de 3,3 a 4,3 litros, previamente destorroadas e peneiradas, foram acondicionadas em bandejas de polietileno, com área superficial de $792 \mathrm{~cm}^{2}$, durante o período de outubro de 2018 a junho de 2019. Para cada bandeja, que correspondeu a um único local de coleta, foi quantificado o número de plântulas emergidas. Foram consideradas emersas as plântulas que apresentavam parte aérea superior a $1 \mathrm{~cm}$, as quais foram identificadas a nível de família e gênero.

A identificação das plantas daninhas ocorreu por meio de literatura especializada (KISSMANN; GROTH, 1997; KISSMANN; GROTH, 2000a; KISSMANN; GROTH, 2000b). Quando não foi possível a identificação em plântulas, foram realizados transplantes para vasos e o cultivo das plantas até o período reprodutivo, sendo posteriormente realizada a identificação. A cada fluxo de emergência e após a estabilização do número de plântulas, o solo das bandejas foi mobilizado para permitir nova emergência. Esse procedimento foi realizado por quatro vezes durante o período do estudo. 
A. L. SILVA

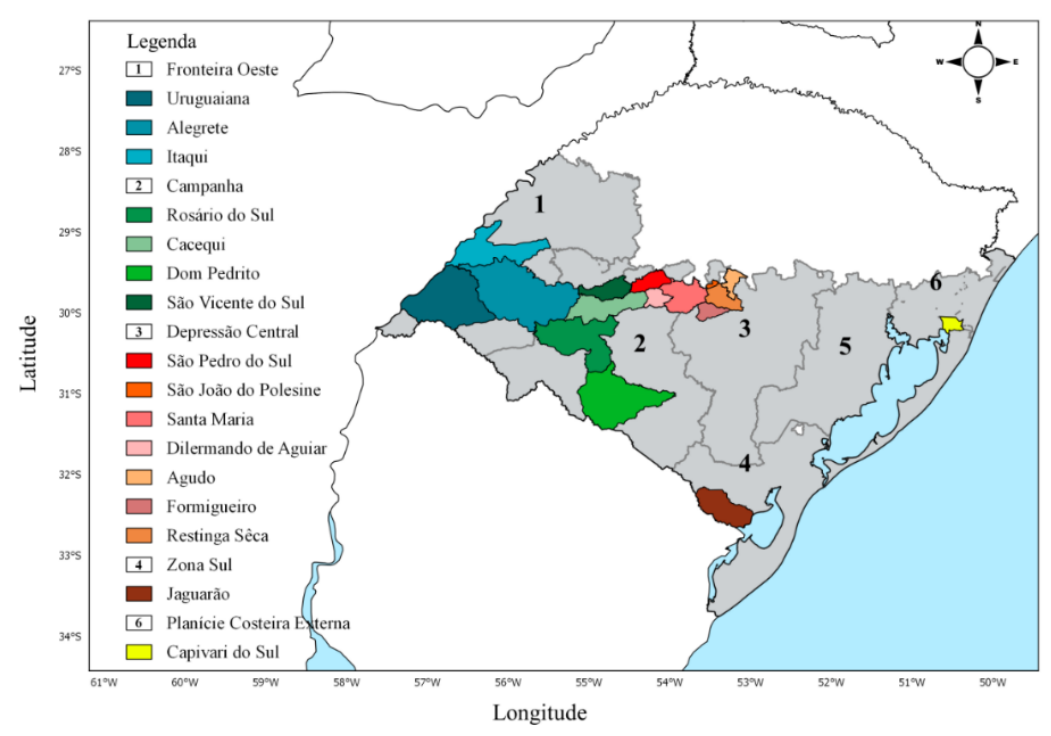

Figura 1. Macrorregiões produtoras de arroz irrigado no Rio Grande do Sul (RS) e cidades que participaram do levantamento fitossociológico.

Com base nos dados quantitativos das diferentes plantas registradas, calcularam-se as variáveis fitossociológicas. Isso foi feito por meio de fórmulas propostas por Mueller-Dombois e Ellenberg (1974), conforme segue abaixo:

Frequência $($ Fre $)=n^{\circ}$ de parcelas que contêm o gênero $/ \mathrm{n}^{\circ}$ total de bandejas utilizadas;

Densidade $($ Den $)=\mathrm{n}^{\circ}$ total de indivíduos utilizados/ área total da bandeja;

Abundância $(\mathrm{Abu})=\mathrm{n}^{\circ}$ de indivíduos por gênero $/ \mathrm{n}^{\circ}$ de bandejas que contêm o gênero;

Frequência relativa (Frr) $=$ frequência $\times 100 /$ frequência total de todos os gêneros;

Densidade relativa $($ Der) $=$ densidade da gênero $\mathrm{x}$ 100/densidade total dos gêneros;

Abundância relativa $(\mathrm{Abr})=$ abundância de gênero $\mathrm{x}$ 100/abundância total dos gêneros;

Índice de valor de importância (IVI) $=$ Frr+Der+Abr.

O cálculo da frequência (Fre) avalia a distribuição das espécies, a densidade (Den), determina a quantidade de plantas de cada espécie por unidade de área, enquanto que a abundância ( $\mathrm{Abu}$ ) informa a respeito da concentração das espécies nas áreas. A associação dessas variáveis, ou seja, frequência relativa (Frr), densidade relativa (Der) e abundância relativa (Abr) informam a relação de cada espécie com as demais espécies encontradas. Já o índice de valor de importância (IVI), determina as espécies mais importantes nas áreas estudadas no levantamento. Para construção da representação gráfica do mapeamento, conforme a distribuição de ocorrência das plantas daninhas, no estado do RS, empregou-se a ferramenta Quantum GIS versão 2.18.0, com base nos resultados obtidos no índice de valor de importância, com valores superiores ou iguais a $16 \%$.

Para avaliação da ocorrência de resistência nas áreas onde foram coletadas as amostras de solo, as plântulas do gênero Cyperus foram transplantadas para bandejas de polietileno com área superficial de $792 \mathrm{~cm}^{2}$, preenchidas com mistura de solo proveniente de terras baixas e substrato comercial na proporção de 1:1. Cada bandeja continha seis linhas com seis plantas transplantadas de locais distintos, espaçadas a $6 \mathrm{~cm}$, utilizando-se o gênero supracitado pela disponibilidade de plantas para o experimento. As amostras de solo de Alegrete (Fronteira Oeste), Cacequi, Dom Pedrito e São Vicente (Campanha), e Agudo (Depressão Central) não apresentaram emergência de Cyperus ou em densidade muito baixa, apresentando insuficiência amostral para aplicação do herbicida.

Quando as plantas encontravam-se no estádio de desenvolvimento de três a quatro folhas, foi realizada aplicação de imazethapyr (Zethapyr $106 \mathrm{SL}, 159 \mathrm{~g} \mathrm{ha}^{-1}$ i.a., SL, Nufarm). A aplicação dos herbicidas foi realizada com auxílio de pulverizador costal, pressurizado a $\mathrm{CO}_{2}$, munido com pontas do tipo leque 110.01 e calibrado para proporcionar volume de aplicação de $150 \mathrm{~L} \mathrm{ha}^{-1}$.

A variável analisada foi o controle visual aos 28 dias após a aplicação dos herbicidas (DAA), utilizando-se escala percentual na qual, zero $(0)$ representou ausência de injúrias e cem (100) a morte de plantas (FRANS, 1972). Plantas daninhas com o controle inferior a $50 \%$ foram consideradas possivelmente resistentes. Posteriormente, para a análise dos resultados obtidos, foi adotada uma escala binária onde 1 representou a morte da planta e 0 sua sobrevivência, indicando a susceptibilidade e resistência do biótipo.

\section{Resultados e Discussão}

Nas 36 amostras de solo coletadas, em áreas com o cultivo de arroz irrigado, foram identificados 38 gêneros de plantas daninhas, distribuídos em 20 famílias botânicas, com cerca de $66 \%$ desses pertencentes à classe das dicotiledôneas (Tabela 1). Esses resultados sugerem uma 
A. L. SILVA

alta diversidade da comunidade infestante em cultivos de arroz irrigado no RS. Provavelmente, isso se deve às condições edafoclimáticas distintas e, principalmente, à diversidade dos sistemas de cultivo, que compreendem os aspectos quanto à forma, à época de preparo do solo, aos métodos de semeadura e ao manejo inicial da irrigação, os quais atuam na dinâmica das populações das espécies daninhas presentes nas diferentes regiões orizícolas do RS (SOSBAI, 2018).

Tabela 1. Distribuição por família e gênero em áreas de produção de arroz irrigado no sistema Clearfield ${ }^{\circledR}$ no Rio Grande do Sul

\begin{tabular}{|c|c|}
\hline Família & Gênero \\
\hline Aizoaceae $^{I}$ & Moluggo \\
\hline Alismataceae & Sagittaria \\
\hline Asteraceae & Conyza \\
\hline Asteraceae & Eclipta \\
\hline Asteraceae & Gamochaeta \\
\hline Asteraceae & Ambrosia \\
\hline Asteraceae & Bidens \\
\hline Asteraceae & Soliva \\
\hline Asteraceae & Ageratum \\
\hline Asteraceae & Pluchea \\
\hline Brassicaceae & Coronopus \\
\hline Caryophyllaceae & Spergula \\
\hline Caryophyllaceae & Cerastium \\
\hline Cyperaceae & Fimbristylis \\
\hline Cyperaceae & Cyperus \\
\hline Cyperaceae & Eleocharis \\
\hline Euphorbiaceae & Phyllanthus \\
\hline Fabaceae & Aeschynomene \\
\hline Lamiaceae & Stachys \\
\hline Lythraceae & Cuphea \\
\hline Malvaceae & Sida \\
\hline Onagraceae & Ludwigia \\
\hline Oxalidaceae & Oxalis \\
\hline Poaceae & Oryza \\
\hline Poaceae & Lolium \\
\hline Poaceae & Piptochaetium \\
\hline Poaceae & Eleusine \\
\hline Poaceae & Echinochloa \\
\hline Poaceae & Digitaria \\
\hline Poaceae & Panicum \\
\hline Poaceae & Urochloa \\
\hline Poaceae & Cynodon \\
\hline Polygonaceae & Polygonum \\
\hline Pontederiaceae & Heteranthera \\
\hline Portulacaceae & Portulaca \\
\hline Rubiaceae & Spermacoce \\
\hline Scrophulariaceae & Scoparia \\
\hline Solanaceae & Solanum \\
\hline
\end{tabular}

${ }^{1}$ Apenas os gêneros das plantas daninhas identificadas.

Além disso, observou-se que a principal família encontrada foi a Poaceae, com um total de nove gêneros, seguido por Asteraceae, Cyperaceae e Caryophyllaceae, com oito, três e dois gêneros, respectivamente (Tabela 1). O referido resultado foi semelhante ao observado em estudos anteriores, nos quais a Família Poaceae foi a mais representativa em levantamentos fitossociológicos realizados em áreas com cultivo de arroz em terras baixas e altas (ERASMO; PINHEIRO; COSTA, 2004; SILVA et al., 2017; NUNES; SCHAEDLER; CHIAPINOTTO, 2018).

Os maiores números de gêneros identificados pertencem às famílias Poaceae e Asteraceae. Esses, juntos, correspondem aproximadamente a $45 \%$ do total de plantas amostradas nesse estudo (Tabela 1). Da mesma forma, das plantas daninhas presentes, em áreas agrícolas do Brasil, destacam-se as famílias Asteraceae e Poaceae (ADEGAS et al., 2010). A maior riqueza dessas famílias, igualmente, foi verificada em diversas culturas agrícolas, como o girassol (ADEGAS et al., 2010), a soja (DIAS et al., 2018), a mandioca (CARDOSO et al., 2013) e o milheto (TEODORO et al., 2015). Todavia, nota-se que muitas das plantas daninhas observadas, no presente estudo, não são relatadas, com frequência, como infestantes de lavouras de arroz irrigado em função da baixa adaptabilidade ao ambiente alagado, destacando-se, assim, as plantas da Família Poaceae e Cyperaceae. 
A. L. SILVA

Os gêneros Cyperus, Echinochloa, Oryza e Lolium apresentaram os maiores valores para o índice de valor de importância (IVI) em relação à comunidade infestante observada no estudo (Tabela 2). Em relação aos parâmetros fitossociológicos, o IVI é um importante parâmetro, pois avalia a real importância de uma planta daninha em um sistema agrícola. Nesse sentido, observa-se que os gêneros citados se caracterizam pela elevada produção de sementes e de propágulos, facilitando sua dispersão e sua colonização em diferentes ecossistemas (KISSMANN; GROTH, 1997). Além disso, apresentam espécies com casos registrados de resistência às imidazolinonas, as quais caracterizam os herbicidas utilizados em lavouras de arroz irrigado e pertencentes ao sistema CL.

Tabela 2. Fitossociologia em áreas de produção de arroz irrigado no sistema Clearfield ${ }^{\circledR}$ no Rio Grande do Sul.

\begin{tabular}{|c|c|c|c|c|c|c|c|}
\hline Gênero & Fre $^{1}$ & $\operatorname{Den}\left(\mathrm{pl} \mathrm{m}{ }^{-2}\right)$ & $\mathrm{Abu}$ & Frr (\%) & Der (\%) & Abr (\%) & IVI \\
\hline Cyperus & 0,94 & 1747 & 138,35 & 8,74 & 25,99 & 25,99 & 60,72 \\
\hline Echinochloa & 0,86 & 600 & 47,48 & 7,97 & 8,92 & 8,92 & 25,81 \\
\hline Oryza & 0,89 & 298 & 23,63 & 8,23 & 4,44 & 4,44 & 17,10 \\
\hline Lolium & 0,44 & 401 & 31,75 & 4,11 & 5,96 & 5,96 & 16,04 \\
\hline Portulaca & 0,11 & 470 & 37,25 & 1,03 & 7,00 & 7,00 & 15,02 \\
\hline Eleusine & 0,42 & 319 & 25,27 & 3,86 & 4,75 & 4,75 & 13,35 \\
\hline Coronopus & 0,69 & 167 & 13,20 & 6,43 & 2,48 & 2,48 & 11,39 \\
\hline Digitaria & 0,47 & 193 & 15,29 & 4,37 & 2,87 & 2,87 & 10,12 \\
\hline Spergula & 0,28 & 237 & 18,80 & 2,57 & 3,53 & 3,53 & 9,63 \\
\hline Scoparia & 0,61 & 90 & 7,14 & 5,66 & 1,34 & 1,34 & 8,34 \\
\hline Oryza ${ }^{2}$ & 0,31 & 166 & 13,18 & 2,83 & 2,48 & 2,48 & 7,78 \\
\hline Eclipta & 0,47 & 102 & 8,12 & 4,37 & 1,52 & 1,52 & 7,42 \\
\hline Ludwigia & 0,53 & 80 & 6,37 & 4,88 & 1,20 & 1,20 & 7,28 \\
\hline Fimbristylis & 0,14 & 152 & 12,00 & 1,29 & 2,25 & 2,25 & 5,79 \\
\hline Aeschynomene & 0,39 & 47 & 3,71 & 3,60 & 0,70 & 0,70 & 4,99 \\
\hline Cerastium & 0,19 & 79 & 6,29 & 1,80 & 1,18 & 1,18 & 4,16 \\
\hline Gamochaeta & 0,25 & 51 & 4,00 & 2,31 & 0,75 & 0,75 & 3,82 \\
\hline Panicum & 0,28 & 34 & 2,70 & 2,57 & 0,51 & 0,51 & 3,59 \\
\hline Piptochaetium & 0,19 & 47 & 3,71 & 1,80 & 0,70 & 0,70 & 3,20 \\
\hline Heteranthera & 0,17 & 48 & 3,83 & 1,54 & 0,72 & 0,72 & 2,98 \\
\hline Sagittaria & 0,08 & 72 & 5,67 & 0,77 & 1,06 & 1,06 & 2,90 \\
\hline Cuphea & 0,03 & 88 & 7,00 & 0,26 & 1,32 & 1,32 & 2,89 \\
\hline Eleocharis & 0,17 & 36 & 2,83 & 1,54 & 0,53 & 0,53 & 2,61 \\
\hline Moluggo & 0,08 & 55 & 4,33 & 0,77 & 0,81 & 0,81 & 2,40 \\
\hline Polygonum & 0,06 & 63 & 5,00 & 0,51 & 0,94 & 0,94 & 2,39 \\
\hline Oxalis & 0,11 & 32 & 2,50 & 1,03 & 0,47 & 0,47 & 1,97 \\
\hline Soliva & 0,11 & 25 & 2,00 & 1,03 & 0,38 & 0,38 & 1,78 \\
\hline Sida & 0,06 & 38 & 3,00 & 0,51 & 0,56 & 0,56 & 1,64 \\
\hline Bidens & 0,08 & 25 & 2,00 & 0,77 & 0,38 & 0,38 & 1,52 \\
\hline Spermacoce & 0,08 & 25 & 2,00 & 0,77 & 0,38 & 0,38 & 1,52 \\
\hline Urochloa & 0,08 & 21 & 1,67 & 0,77 & 0,31 & 0,31 & 1,40 \\
\hline Solanum & 0,06 & 25 & 2,00 & 0,51 & 0,38 & 0,38 & 1,27 \\
\hline Pluchea & 0,03 & 25 & 2,00 & 0,26 & 0,38 & 0,38 & 1,01 \\
\hline Cynodon & 0,03 & 25 & 2,00 & 0,26 & 0,38 & 0,38 & 1,01 \\
\hline Conyza & 0,06 & 13 & 1,00 & 0,51 & 0,19 & 0,19 & 0,89 \\
\hline Stachys & 0,06 & 13 & 1,00 & 0,51 & 0,19 & 0,19 & 0,89 \\
\hline Ambrosia & 0,03 & 13 & 1,00 & 0,26 & 0,19 & 0,19 & 0,63 \\
\hline Phyllanthus & 0,03 & 13 & 1,00 & 0,26 & 0,19 & 0,19 & 0,63 \\
\hline Ageratum & 0,03 & 13 & 1,00 & 0,26 & 0,19 & 0,19 & 0,63 \\
\hline Não identificado - 1 & 0,50 & 173 & 13,72 & 4,63 & 2,58 & 2,58 & 9,78 \\
\hline Não identificado - 2 & 0,11 & 284 & 22,50 & 1,03 & 4,23 & 4,23 & 9,48 \\
\hline Não identificado - 3 & 0,53 & 94 & 7,42 & 4,88 & 1,39 & 1,39 & 7,67 \\
\hline Não identificado - 4 & 0,14 & 71 & 5,60 & 1,29 & 1,05 & 1,05 & 3,39 \\
\hline Não identificado - 5 & 0,08 & 63 & 5,00 & 0,77 & 0,94 & 0,94 & 2,65 \\
\hline Não identificado - 6 & 0,03 & 51 & 4,00 & 0,26 & 0,75 & 0,75 & 1,76 \\
\hline Não identificado - 7 & 0,03 & 25 & 2,00 & 0,26 & 0,38 & 0,38 & 1,01 \\
\hline Não identificado - 8 & 0,03 & 13 & 1,00 & 0,26 & 0,19 & 0,19 & 0,63 \\
\hline
\end{tabular}

${ }^{1}$ Frequência (Fre), densidade (Den), abundância (Abu), frequência relativa (Frr), densidade relativa (Der), abundância relativa (Abr) e índice de valor de importância (IVI). ${ }^{2}$ arroz cultivado (Oryza sativa). 
A. L. SILVA

O aumento da frequência e da densidade de plantas daninhas resistentes a herbicidas deve-se ao fato da sobrevivência das mesmas durante o cultivo do arroz e, consequentemente, à chuva de sementes, que proporciona aumento do banco de sementes e de propágulos no solo. O monocultivo de arroz CL, associado ao uso exclusivo de controle químico com o mesmo mecanismo de ação, selecionou plantas daninhas resistentes, destacando-se o problema crescente de casos de Cyperus no RS (ULGUIM et al., 2019), que pode explicar o maior IVI observado, para esse gênero, comparativamente aos demais (Tabela 2).

$\mathrm{O}$ gênero Cyperus predominou nas áreas amostradas, com valores superiores aos demais presentes em todos os parâmetros fitossociológicos avaliados (Tabela 2). Esse resultado corrobora com estudo realizado om a cultura de arroz irrigado, em que constatou a espécie do gênero Cyperus como predominante no banco de sementes em sistema de cultivo com plantio direto e rotação de culturas (ULGUIM et al., 2018). Nesse sentido, o predomínio desse gênero pode ser atribuído à sua ampla adaptabilidade aos diferentes ambientes agrícolas, preferencialmente por solos úmidos ou inundados e pela capacidade de se reproduzir sexuada e assexuadamente (KISSMANN; GROTH, 1997), o que torna mais difícil o controle das suas espécies. Neste contexto, as espécies Cyperus esculentus L., C. ferax L. C. Rich., C. difformis L. e C. iria $\mathrm{L}$. destacam-se em áreas de arroz irrigado do Sul do Brasil. Salienta-se, também, que o fato de o estudo ser conduzido em ambiente controlado pode ter favorecido a emergência dessas plantas daninhas. Dessa forma, é importante que se realizem mais estudos a campo para corroborar ou a fim de refutar essas observações.

O complexo do gênero Echinochloa, no qual se destacam as espécies Echinochloa colona (L.) Link, E. crusgalli (L.) P.Beauv. e E. crus-pavonis (Kunth) Schult. (NUNES; SCHAEDLER; CHIAPINOTTO, 2018; KISSMANN; GROTH, 1997), foi o segundo gênero com maior IVI, apresentando uma elevada frequência e densidade de 600 plantas $\mathrm{m}^{-2}$ (Tabela 2). Em condições de áreas de produção, identificou-se densidade de Echinochloa spp. com cerca de 10 plantas $\mathrm{m}^{-2}$, evidenciando alto IVI durante a fase inicial de crescimento do arroz com tecnologia CL na Fronteira Oeste do RS (NUNES; SCHAEDLER; CHIAPINOTTO, 2018). Esse gênero representa mais de $80 \%$ das plantas daninhas que ocorrem nas lavouras de arroz irrigado no RS e tem, como características, ciclo fotossintético $\mathrm{C} 4$, elevado número de produção de sementes, rápido crescimento $\mathrm{e}$ desenvolvimento inicial, as quais indicam alta habilidade de competição com a cultura (AGOSTINETTO et al., 2008). Ademais, foi averiguado um elevado número de casos de resistência, com relatos de resistência múltipla aos herbicidas mimetizadores de auxinas, herbicidas inibidores da enzima acetil coenzima-A carboxilase (ACCase) e da acetolactato sintase (ALS) (EBERHARDT et al., 2016).

O gênero Oryza apresentou IVI de 17,10 e frequência de 0,89 , considerando-se a variável fitossociológica que mais contribuiu para elevar o IVI (Tabela 2), evidenciando a ampla ocorrência desse gênero nas áreas de arroz irrigado. Entre as espécies desse gênero, destaca-se o arroz-daninho, considerada a principal planta daninha infestante em cultivos de arroz irrigado (ROSO et al., 2010). Alto degrane, dormência fisiológica e longevidade das sementes, no solo, são algumas características importantes, as quais conferem, a essa espécie, maior habilidade competitiva frente às demais (THURBER et al., 2010). O arroz-daninho, por pertencer à mesma espécie que o arroz cultivado, apresentase como uma planta de difícil controle com uso de herbicidas, podendo ser, atualmente, controlado somente de forma seletiva, mediante tecnologia CL.

No entanto, devido à pressão de seleção pelo uso inadequado e continuo por três a quatro anos da tecnologia CL, houve o surgimento de diversas populações de arrozdaninho resistentes a herbicidas do grupo químico das imidazolinonas nas regiões orizícolas do RS (MEROTTO et al., 2016). Nesse caso, em decorrência da alta frequência observada para essa planta daninha (Tabela 2), destaca-se que grande parte da área de cultivo de arroz irrigado, no RS, encontra-se com infestação de arroz-daninho e com potencial de resistência. Desse modo, práticas de manejo têm sido desenvolvidas para o controle dessa planta daninha, destacando-se a rotação de culturas com a soja e novas tecnologias de tolerância do arroz a herbicidas inibidores da ACCase.

O IVI do gênero Lolium foi o quarto maior encontrado no presente estudo (Tabela 2), representado pela espécie L. multiflorum L.. Assim, a presença de Lolium, nas áreas de arroz irrigado, pode se dar em decorrência do uso dessa forrageira anual de inverno como pastejo, durante o período da entressafra, associado à sua alta capacidade de ressemeadura natural, (BARBOSA et al., 2008; MARCHESAN et al., 2011). Entretanto, vale destacar que as plantas do gênero Lolium não podem ser consideradas, até o presente momento, como sendo um problema na pósemergência do arroz irrigado, devido à suscetibilidade à submersão.

As principais espécies de plantas daninhas infestantes, nas áreas com cultivo de arroz irrigado, no RS, pertencem aos gêneros Cyperus, Echinochloa e Oryza, os quais são responsáveis por elevadas perdas na produtividade de grãos. No mapeamento da distribuição desses gêneros de plantas daninhas, encontrados no presente estudo, notou-se que eles ocorrem em elevada frequência e estão amplamente distribuídos nas cinco regiões produtoras amostradas do RS (Figura 2).

Em relação ao número de propriedades $(\mathrm{n}=36)$, a ocorrência de Cyperus, Echinochloa e Oryza deu-se em 34, 31 e 32 propriedades, respectivamente (Figura 2). Em contrapartida, o gênero Lolium esteve presente em apenas 16 propriedades, distribuídas em nove municípios (Figura 2). Nesse trabalho, pode ser observado que os gêneros Cyperus, Echinochloa e Oryza têm grande representação nas áreas produtoras de arroz irrigado, com elevada frequência e densidade, podendo interferir negativamente na produtividade da cultura se não manejados de forma adequada. Além disso, destaca-se que há registros de ocorrência de resistência aos herbicidas do grupo químico das imidazolinonas para plantas daninhas pertencentes aos gêneros mencionados anteriormente, com potencial dificuldade do manejo químico nas áreas que utilizam a Tecnologia CL. 


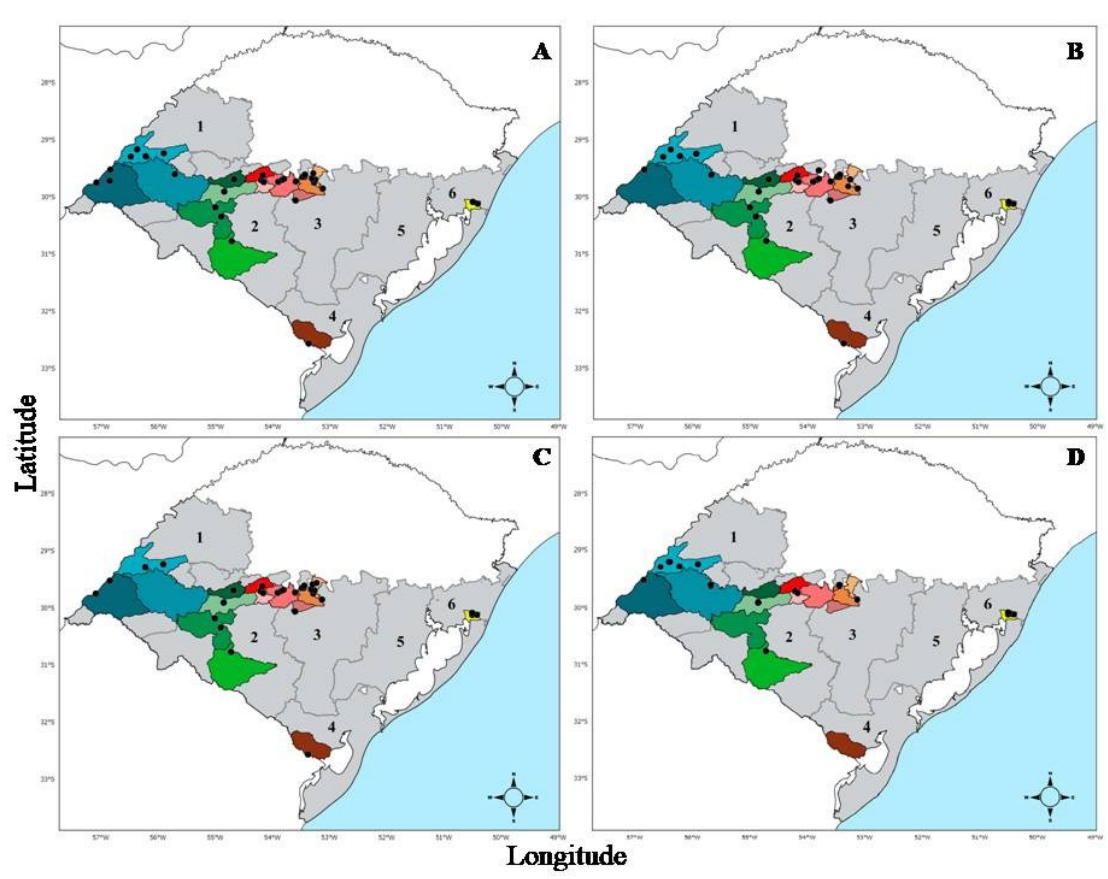

Figura 2. Mapeamento da distribuição geográfica da ocorrência das plantas daninhas dos gêneros (A) Cyperus, (B) Echinochloa, (C) Oryza e (D) Lolium amostradas nas regiões orizícolas do estado do Rio Grande do Sul. 1) Fronteira Oeste, 2) Campanha, 3) Depressão Central, 4) Zona Sul e 5) Planície Costeira Externa. (n) = 36.

A avaliação da resposta de controle de plantas do gênero Cyperus mediante aplicação de imazethapyr indicou $15 \%$ de sobrevivência (Tabela 3), resultado condizente com trabalho que fez o mapeamento dos casos de resistência de plantas da Família Cyperaceae em arroz irrigado (ULGUIM et al., 2019). Destaca-se que a avaliação em plantas do gênero Cyperus deu-se em decorrência do maior IVI para esse gênero na análise de fitossociologia (Tabela 1), sugerindo a ampla distribuição dessas espécies e o elevado risco de resistência das mesmas. Além disso, destaca-se que embora a resistência de plantas daninhas em áreas de arroz irrigado seja um dos principais problemas envolvidos no manejo da cultura, há muitas áreas de produção em que os problemas estão minimizados. Essa inferência pode ser baseada nas práticas de manejo adotadas recentemente nessas áreas, como a rotação de culturas, sistemas conservacionistas de solo, rotação de mecanismos de ação, uso de glifosato em ponto-de-agulha, entre outras (ULGUIM et al., 2018; ULGUIM et al., 2019; FRUET; MEROTTO; ULGUIM, 2019).

Tabela 3. Controle de plantas do gênero Cyperus oriundas de áreas de produção de arroz irrigado no sistema Clearfield ${ }^{\circledR}$ no Rio Grande do Sul, aos 28 dias após a aplicação de imazethapyr.

\begin{tabular}{ccc}
\hline Região produtora & Município da coleta & Controle $^{1}$ \\
& Itaqui & 1 \\
Fronteira Oeste & & 1 \\
& Uruguaiana & 1 \\
& & 1 \\
Campanha & Rosário do Sul & 1 \\
\hline & Dilermando de Aguiar & 0 \\
\hline & Formigueiro & 1 \\
& & 1 \\
Depressão Central & Restinga Sêca & 1 \\
& & 1 \\
& Santa Maria & 1 \\
& & 1 \\
& São João Polêsine & 1 \\
& São Pedro do Sul & 1 \\
\hline Zona Sul & Jaguarão & 0 \\
\hline Planície Costeira Externa & Capivari & 1 \\
\hline
\end{tabular}

${ }^{1}$ Escala binária, onde 1 e 0 representa plantas mortas (suscetível) e plantas sobreviventes (possivelmente resistente), respectivamente.

Rev. Bras. Herb., v. 19, n. 3, e. 724, jul./set., 2020 
A. L. SILVA

\section{Conclusões}

As áreas com o cultivo de arroz irrigado, no sistema Clearfield $^{\circledR}$, apresentam alta diversidade e distribuição de plantas daninhas, e os gêneros Cyperus, Echinochloa, Oryza e Lolium possuem os maiores índices de valor de importância (IVI).

Plantas daninhas do gênero Cyperus apresentam maiores valores para frequência, densidade e abundância relativas, bem como alto índice de valor de importância dentre as demais observadas.

A aplicação de imazethapyr em plantas do gênero Cyperus evidencia 15\% de sobrevivência de plantas.

\section{Agradecimentos}

Os autores agradecem à Fundação de Amparo à Pesquisa do Rio Grande do Sul (FAPERGS), pelo apoio financeiro através do Edital 01/2017.

\section{Referências}

Adegas, F. S.; Oliveira, M. F.; Vieira, O. V.; Prete, C. E. C.; Gazzieiro, D. L. P; Voll, E. Levantamento fitossociológico de plantas daninhas na cultura do girassol. Planta Daninha, v. 28, n. 4 , p. $705-716,2010$.

Agostinetto, D.; Galon, L.; Moraes, P. V. D.; Rigoli, R. P.; Tironi, S. P.; Panozzo, L. E. Competitividade relativa entre cultivares de arroz irrigado e biótipo de capim-arroz (Echinochloa spp.). Planta Daninha, v. 26, n. 4, p. 757-766, 2008.

Barbosa, C. M. P.; Carvalho, P. C. F.; Cauduro, G. F.; Devincenzi, T.; Nabinger, C.; Jacques, A. V. A. Efeito de métodos e intensidades de pastejo sobre a ressemeadura natural de azevém anual. Acta Scientiarum Animal Science, v. 30, n. 4, p. 387-393, 2008.

Cardoso, A. D.; Viana, A. E. S.; Barbosa, R. P.; Teixeira, P. R. G.; Cardoso Júnior, N. S.; Fogaça, J. J. N. L. Levantamento fitossociológico de plantas daninhas na cultura da mandioca em Vitória da Conquista Bahia. Bioscience Journal, v. 29, n. 5, p. 1130-1140, 2013.

Christensen, S. D.; Ransom, C. V.; Edvarchuk, K.A.; Rasmussen, V. P. Efficiency and accuracy of wildland weed mapping methods. Invasive Plant Science and Management, v. 4, n. 4, p. 458-465, 2011.

Concenço, G.; Tomazi, M.; Correia, I. V. T.; Santos, S. A.; Galon, L. Phytosociological surveys: tools for Weed Science?. Planta Daninha, v. 31, n. 2, p. 469-482, 2013.

Dias, M. F.; Krenchinski, F. H.; Pereira, V. G. C.; Moreno, G.; Albrecht, L. P.; Albrecht, A. J. P. Phytosociological survey of weeds in glyphosate resistant and susceptible soybean cultivation areas. Revista Brasileira de Ciências Agrárias, v. 13, n. 4, p. 1-7, 2018.

Eberhardt, D. S.; Oliveira Neto, A. M.; Noldin, J. A.; Vanti, R. M. Barnyardgrass with multiple resistance to synthetic auxin, ALS and Accase inhibitors. Planta Daninha, v. 34, n. 4, p. 823-832, 2016.

Erasmo, E. A. L.; Pinheiro, L. L. A.; Costa, N. V. Levantamento fitossociológico das comunidades de plantas infestantes em áreas de produção de arroz irrigado cultivado sob diferentes sistemas de manejo. Planta Daninha, v. 22, n. 2, p. 195-201, 2004.

Frans, R. E. Measuring plant responses. In: Wilkinson, R.E. (Ed.). Research methods in weed science. Puerto Rico: Southern Weed Science Society, 1972. p. 28-41.

Fruet, B. L.; Merotto, A.; Ulguim, A. R. Survey of rice weed management and public and private consultant characteristics in Southern Brazil. Weed Technology, v. 27, p. 1-6, 2019.

IRGA - Instituto Rio Grandense do Arroz. Boletim de resultados da lavoura de arroz safra 2017/18. Disponível em: <www.irga.rs.gov.br>. Acesso em: 02 dez. 2019.

Kissmann, K.G.; Groth, D. Plantas infestantes e nocivas. Tomo I. 2. ed. São Paulo: BASF, 1997. 825 p.

Kissmann, K. G.; Groth, D. Plantas infestantes e nocivas. Tomo II. 2. ed. São Paulo: BASF, 2000a. 978 p.

Kissmann, K. G.; Groth, D. Plantas infestantes e nocivas. Tomo III. 2. ed. São Paulo: BASF, 2000b. 722 p.

Marchesan, E.; Massoni, P. F. S.; Villa, S. C. C.; Grohs, M.; Avila, L. A.; Sartori, G. M. S. Produtividade, fitotoxicidade e controle de arroz-vermelho na sucessão de cultivo de arroz irrigado no Sistema Clearfield ${ }^{\circledR}$. Ciência Rural, v. 41, n. 1, p. 17-24, 2011.

Menezes, V. G., Mariot, C. H. P.; Kalsing, A.; Goulart, I. C. G. R. Arroz-vermelho (Oryza sativa) resistente aos herbicidas imidazolinonas. Planta Daninha, v. 27, p. 10471052, 2009.

Merotto, A.; Goulart, I. C. G. R.; Nunes, A. L.; Kalsing, A.; Markus, C.; Menezes, V. G.; Wander, A. E. Evolutionary and social consequences of introgression of nontransgenic herbicide resistance from rice to weedy rice in Brazil. Evolutionary Applications, v. 9, n. 7, p. 837-846, 2016.

Mueller-Dombois, D.; Ellenberg, H. Aims and methods of vegetation ecology. New York: John Wiley e Sons, p. 547, 1974.

Nunes, F. S.; Schaedler, C. E.; Chiapinotto, D. M. Weed phytosociological survey in irrigated rice. Planta Daninha, v. 36, p. 1-9, 2018. 
Ribas, G. G.; Streck, N. A.; Lago, I.; Zanon, A. J.; Waldow, D. A. G.; Duarte Junior, A. J.; et al. Acúmulo de matéria seca e produtividade em híbridos de arroz irrigado simulados com o modelo SimulArroz. Pesquisa Agropecuária Brasileira, v. 51, p. 1907-1917, 2016.

Roso, A. C.; Merotto, A.; Delatorre, C. A.; Menezes, V. G. Regional scale distribution of imidazolinone herbicideresistant alleles in red rice (Oryza sativa L.) determined through SNP markers. Field Crops Research, v. 119, p. 175 $-182,2010$.

Silva, M. R. M.; Costa, E. A.; Corrêa, M. J. P.; Rodrigues, A. A. C.; Mesquita, M. L. R. Floristic and phytosociology of weeds in upland rice in the humid tropics. Planta Daninha, v. 35, p. 1-11, 2017.

Sociedade Sul-Brasileira de Arroz Irrigado - SOSBAI. Arroz irrigado: recomendações técnicas da pesquisa para o Sul do Brasil. Cachoeirinha: SOSBAI, 2018. 209 p.

Teodoro, P. E.; Ribeiro, L. P.; Corrêa, C. C. G.; Luz Júnior, R. A. A.; Souza, M. C.; Simões, M. S. Phytosociology of weeds in millet under different soil managements in savanna Sul-Mato-Grossense. Bioscience Journal, v. 31, n. 4, 2015.

Thurber, C. S.; Reagon, M.; Gross, B. L.; Olsen, K. M.; Jia, Y.; Caicedo, A. L. Molecular evolution of shattering loci in U.S. weedy rice. Molecular Ecolology, v. 19, n. 16, p. 3271 $-3284,2010$.

Ulguim, A. R.; Silva, B. M.; Agostinetto, D.; Avila Neto, R. C.; Zandoná, R. R. Resistance mapping of the genus Cyperus in Rio Grande do Sul and selection pressure analysis. Planta Daninha, v. 37, p. 1-8, 2019.

Ulguim, A. R.; Carlos, F. S.; Santos, R. A. S.; Zanon, A. J.; Werle, I. S.; Beck, M. Weed phytosociological in irrigated rice under different cultivation systems and crop rotation intensity. Ciência Rural, v. 48, n. 11, p. 1-7, 2018.

Zhang, Z.; Gua, T.; Zhao, B.; Yanga, X.; Pengc, Q.; Li, Y. Effects of common Echinochloa varieties on grain yield and grain quality of rice. Field Crops Research, v. 203, p. 163172. 2017. 